\title{
COMPARATIVE EVALUATION OF HISTOTOXICITY INDICATORS OF METAL ALLOYS FOR THE MANUFACTURE OF METAL CERAMIC DENTAL CONSTRUCTIONS
}

DOI: 10.36740/WLek202109113

\author{
Petro A. Hasiuk', Mykhailo Ramus², Anna Vorobets' ${ }^{1}$ Iryna Tkachenko², Tetiana Dzetsiukh', Dmytro Kalashnikov², \\ Svitlana Rosolovska' ${ }^{1}$ \\ II. HORBACHEVSKY TERNOPIL NATIONAL MEDICAL UNIVERSITY, TERNOPIL, UKRAINE \\ 2POLTAVA STATE MEDICAL UNIVERSITY, POLTAVA, UKRAINE
}

\begin{abstract}
The aim: To carry out a comparative assessment of metal alloys for the manufacture of metal-ceramic constructions of dentures by determining the indicator of their histotoxicity. Materials and methods: To identify the effect of metal alloys on cobalt and nickel bases on the tissue of organism, we carried out an experimental-morphological study of standard samples of metal alloys "Shot-alloy", "Remanium-2000", "Cerium", "Dent-NCB", "Cellite-N".

Results: A careful histological analysis of the capsules formed around the metal alloy samples during two periods of the experiment showed that the healing time of the subcutaneous tissue was not the same. The most complete healing, that is, the formation of mature fibrous connective tissue, occurred during the implantation of the cobaltbased alloy "Remanium-2000" and the capsule formed at the end of the experiment around the implanted sample from the "Shot-alloy" alloy, and during the implantation of the "Cerium" alloy, healing the wound surface and the formation of a connective tissue capsule occurs fully than in previous cases.

Conclusions: The analysis of the performed experiment testifies in favor of the point of view that the speed and quality of healing of damaged subcutaneous tissue upon the introduction of implanted research alloys depend largely on the individual chemical components that make up the alloys, or on their combination.
\end{abstract}

KEY WORDS: metal alloys, metal-ceramic constructions, histotoxic research, tissue culture method

Wiad Lek. 2021;74(9 p.I):2100-2104

\section{INTRODUCTION}

Sufficient attention is paid to the study of the population's need for dental orthopedic care. It should be noted that large-scale preventive measures, improvement of known methods and approaches to treatment, unfortunately, did not significantly reduce the percentage of people with dentition defects [1].

Literature data indicate that the population's need for fixed dental prosthetics is quite high, especially in solid-cast fixed structures of dental prostheses with aesthetic cladding $[2,3]$.

Modern achievements of prosthetic dentistry are largely based on the use of the latest technologies and materials. Increasing the effectiveness of orthopedic treatment is carried out in the following areas: the methods of making fixed prostheses are being improved, new materials are being developed, the principles of making prostheses are changing $[4,5,6]$.

For a successful dental metal-ceramic constructions, the use of both ceramic materials and metal alloys is of great importance. Currently, more than 300 types of metal structures are used for the manufacture of metal-ceramic structures. For a long time, the main structural materials for fixed dentures are cobalt-chromium and nickel-chromium alloys, veneered with ceramic materials $[7,8,9,10]$.
Studies of the effects of metal alloys on the tissues of the oral cavity indicate that the metal ions that are released into the oral fluid, due to the significant permeability of the mucous membrane that adsorbs them, cause toxic effects on the human body. It is known that most modern metal alloys used in dental practice are not completely indifferent to the human body $[11,12]$.

Therefore, the question of studying the indicators of their histotoxicity remains relevant.

\section{THE AIM}

The aim of the research was to carry out a comparative assessment of metal alloys for the manufacture of metal-ceramic constructions of dentures by determining the indicator of their histotoxicity.

\section{MATERIALS AND METHODS}

This study was conducted at the orthopedic dentistry department I. Horbachevsky Ternopil National Medical University, Ukraine, and was approved by the ethics committee of the I. Horbachevsky Ternopil National Medical University. 
The investigations was performed according to the general rules and regulations of the "European Convention for the Protection of Vertebrate Animals Used for Experimental and Other Scientific Purposes" (Strasbourg, 1986) and the "General Ethical Principles of Animal Experimentation" (Kyiv, 2001).

In order to identify the effect of metal alloys on cobalt and nickel bases on the tissue of a living organism, we carried out an experimental-morphological study in accordance with ISO-10993-6: 1994, the essence of which was to carry out the operation of implantation of standard samples of metal alloys, are investigated, namely: "Shot-alloy “, " Remanium-2000 “, "Cerium”, "Dent-NCB “, "Cellite-N “.

The experiment was carried out on white rats (male Wistar line) weighing 180-200 g, which were implanted under the skin in the back region with specimens of the indicated alloys in the form of plates $6 \times 3 \times 2 \mathrm{~mm}$ in size under thiopental anesthesia. The experiment involved 30 white rats.

On the 14th and 30th day, the experimental animals were sacrificed by decapitation under thiopental anesthesia.

After that, the sites of implantation were opened, samples of alloys were taken out, and the tissues that surrounded them were examined.

For histological examination, tissues were fixed in a 10$12 \%$ solution of neutral formalin. After fixation, paraffin blocks were prepared according to the standard technique.

Then, sections of preparations with a thickness of 7-12 $\mu \mathrm{m}$ were made from the blocks. The obtained sections were stained with hemotoxylin-eosin, and Van Gieson's stain was also used to identify connective tissue. Histological preparations were studied at various magnifications with a Biola microscope. Illustrative material was obtained using MFN-10 attachments [11].

Methods of histotoxic research.

Taking into account the fact that these metal alloys have long-term contact with the tissues of the body, and also taking into account the current IS0 standards in the field of medical devices, we conducted studies in accordance with IS0 10993-5: 1992 of the toxicity of metals by the tissue culture method.

The quality control of the experiment was carried out using the tissue culture method. When preparing extracts for the model medium, medium 199 was used. The ratio between the weight of the test material and the volume of the model medium was $100 \mathrm{mg}: 1 \mathrm{ml}$ [11].

The extraction was carried out at a temperature of $37^{\circ}$ C for 3, 7, 10 days. In each experimental group, subgroups were identified: control and experimental. In the control group, tissue culture was carried out on plasma, followed by a change in the medium on days $3,7,10$ of cultivation. In the experimental group, on days $3,7,10$ of cultivation, medium 199 was replaced with prepared extracts. As a source of cells, we used the subcutaneous tissue of white outbred rats, which give growth of fibroblastic and fibroblast-like elements under in vitro cultivation conditions. The choice of this model is due to the following factors: firstly, the cell lines, which are repartitioned, are genetically and metabolically different from the cells of the tissues of the body and, as is known, have greater resistance to harmful influences; secondly, in a toxicological study, their implantation is carried out into the subcutaneous tissue and, therefore, the body's response is mediated through the connective tissue system, the main structural element of which is fibroblasts [11].

The test material was cultivated in a plasma clot using a nutrient medium of the following composition: solid phase - 30\% medium 199 and $20 \%$ bovine serum.

In order to standardize the nature of the growth of cultures, their zones were classified into a compact, reticular and a zone of cells that migrate, the criterion for identifying which was the nature of the location of the growth of fibroblastic elements. The compact zone includes the zone of dense arrangement of rosaceous cells, the reticular zone - the zone of location of anastomosing and branched cell tissues. By the tops of the nutrient medium, which grow in isolation into the solid phase, cell strands and the location of isolated cells, the zone of elements was determined.

Subsequently, on the fifth, seventh, and tenth days of incubation of the cultures, the limits of the compact, sievelike zone of fibroblastic migrating elements were identified on micrographs. Then, with a standardized magnification using a Curvimeter, the total perimeter of the explants $\left(\mathrm{P}_{\mathrm{ex}}\right)$ was determined, as well as its parts corresponding to each growth zone: $\mathrm{P}_{\mathrm{cgz}}$ - for a compact growth zone, $\mathrm{P}_{\mathrm{rgz}}$ for reticular growth zones, $\mathrm{P}_{\mathrm{mez}}$ - for a zone of migrating elements.

For each growth zone, their areas $\left(\mathrm{S}_{\mathrm{cgz}}, \mathrm{S}_{\mathrm{rgz}}, \mathrm{S}_{\mathrm{mez}}\right)$ were determined using morphometric grids with a given node spacing. Based on the data obtained for each growth zone, the zonal growth activity (AG) and the zonal growth intensity were calculated (IG). The perimeter (AG) characterizes the degree of germination of explantation of the subsequent formation of the indicated growth zones at the corresponding time of observation. Parameter (IR) allows you to estimate the size of the area of various growth zones per unit perimeter of the explants.

The parameters AG and IG were calculated by the formulas:

$\mathrm{AG}=\mathrm{P}_{\mathrm{gz}}: \mathrm{P}_{\mathrm{ex}}$

IG $=\mathrm{S}_{\mathrm{gz}} \mathrm{P}: \mathrm{P}_{\mathrm{gz}}$

where ${ }^{\mathrm{gz}} \mathrm{P}_{\mathrm{gz}}$ is a part of the explant perimeter, which corresponds to a certain growth zone, $\mathrm{P}_{\mathrm{ex}}$ is the explant perimeter, $\mathrm{S}_{\mathrm{gz}}$ is the area of the corresponding growth zone.

Along with this, the nature of zonal degeneration in points was assessed during the indicated periods of observation of the cultures. For example, the absence of degeneration - 1 point, the presence of signs of degeneration - 2 points, mass degeneration -3 points.

To determine the effect of the test substance on the growth of tissue culture, an extract from it was introduced into the culture medium on the third day of incubation. Then, the parameters of AG, IG, as well as the degree of cell degeneration on the fifth, seventh, tenth day of cultivation were determined.

Based on the obtained data (parameters), the histotoxicity index (HI) was calculated according to the formula: 
Where - the average size of the zonal activities of fibroblast growth in the experiment, which are observed during the cultivation;

- the sum of the sizes of the average values of the zonal intensity of fibroblast growth in the experiment on the fifth, seventh and tenth days of cultivation;

- the sum of the sizes of the average values of the zonal intensity of fibroblast growth in the control on the fifth, seventh and tenth days of cultivation;

- the sum of the mean values of zonal degeneration of fibroblasts in the experiment on the fifth, seventh, tenth days of cultivation;

$\mathrm{i}$ - data on a table column; $\mathrm{j}$ - data on the row of the table.

$J-1,3$ - row number of the table of average values of fibroblast growth activity: compact zone $\mathrm{j}=1$, mesh zone $j=2$, zone of migrating elements $j=3 ; n$ is the number of observations of indicators of fibroblast growth activity.

When the level of values $\mathrm{HI} \geq 0.72$, the material is characterized as non-toxic; with values of $0.72 \geq \mathrm{HI} \geq 0.48$ - low toxicity; with values of $0.48 \geq \mathrm{HI} \geq 0.27$ - moderately toxic and with values of $0.27>\mathrm{HI}$ - very toxic.

The obtained results were statistically analyzed using the software STATISTICA 10.0 («Statsoft», USA). The reliability of the difference in values between independent quantitative values was determined with the normal distribution by criterion U-criterion Mann-Whitney.

\section{RESULTS}

As mentioned above, experimental studies were carried out on white rats (male Wistar line). The duration of the experiment was: 1 st series - 2 weeks, 2 nd - 4 weeks. After incision of the skin over the implanted samples, in each case, areas of compaction of loose subcutaneous tissue were determined with sizes that slightly exceed the sizes of the studied alloy samples. These areas were carefully dissected, then after opening the tissues surrounding the sample, it was removed, and the remaining capsule was carefully examined. The capsule, which was examined macroscopically, is a thin-walled formation of pale pink color. In some cases, the capsule wall looks denser, in others it is refined and plump.

In more detail, the histological examination of the walls of the capsules in each case allows us to characterize their individual characteristics.

Around the metal alloy «Shot-alloy» in two weeks, a two-layer capsule of different thickness and maturity of fibrous structures is determined. It is characteristic that the inner layer is composed of tightly packed, correctly oriented "young" immature fibers. The outer layer of this capsule is made up of loosely packed medium-sized collagen fibers, among which cellular elements such as fibroblasts, lymphocytes and individual neutrophils are constantly scattered. The wall of the capsule in transverse sections has numerous protrusions into the cavity in the form of papillae of different thickness and height. In the area of these protrusions, in some places, cellular infiltrates are limited. In addition, attention is drawn to the fact of focal exfoliation of the inner layer from the outer. By the end of the experiment, that is, a month after its start, a noticeable thickening of the inner layer of the capsule, as well as a more orderly dispersion of thick collagen fibers. Between them, single hyperemic small blood vessels are scattered, as well as a few cells, mainly fibroblasts and fibrocytes. It is often possible to observe cavities of various configurations and sizes in the protrusions of the capsule wall. The outer layer of the capsule consists of mature thick collagen fibers that form a dense layer. Single fibrocytes, fibroblasts, and round-cell elements are found between the fibers. Blood vessels rarely come into the field of view of the cut.

Investigating the capsule that appeared around the sample of the "Remanium-2000" alloy, 2 weeks after the start of the experiment, we found its clear double-ball. The thickness of both the inner and outer layers along the entire perimeter of the sample bed is not the same. It is characteristic that the inner layer of the capsule in different areas is represented by fibrous structures of various degrees of maturity, it is well manifested in different color densities of histological preparations. As in the previous case, the wall of the capsule forms protrusions into its cavity. But in this case, along with papillary protrusions, trabecular structures appear, move from one wall to the opposite, while separate cells are formed in the capsule cavity.

A feature of trabecular structures is the presence of channels filled with fluid in them. The papillary protrusions of the capsule walls consist of fibrous structures of varying degrees of maturity and different thicknesses. On a longitudinal section of such formations, an accumulation of microvessels in their central part, surrounded by fibers, is clearly detected. The outer layer of the capsule is closely fused with the inner one. It is built from densely packed bundles of thick fibers, turns red when stained according to Van Gieson. A month after the start of the experiment, further maturation of the structures of the capsule wall was noticeable. It is characteristic that in this case the number of blood vessels, as well as cellular elements of the fibroblastic series, decreases significantly. In some areas of such a mature connective tissue capsule, the direction of the location of the fibrous structures is mutually perpendicular, which, obviously, provides reliable isolation of the sample, is investigated, from adjacent tissues.

During the histological examination of the tissues surrounding the Cerium alloy, it was revealed that two weeks after the beginning of the experiment, there was a significant cellular infiltration in the walls of the capsule. In the inner layer of the capsule, fibrous structures permeated with cells, mainly of the fibroblastic series (fibroblasts, fibrocytes). There are a small number of lymphocytes, plasma cells, and neutrophils in between. The outer layer of the capsule wall contains microvessels, and cellular elements are located between its fibers. During the histological examination of the tissues of the capsule that surround the "Cerium" alloy, a month after the start of the experiment, the histological picture is significantly different from the previous terms of the experiment. So, in the inner layer of the capsule, there is a noticeable sharp 
decline in cellular elements. At the same time, the fact of the maturation of the collagen fibers of this layer attracts attention. They look thickened, in addition, their tortuosity decreases, which leads to a tightening of the capsule wall. In the outer layer of the capsule, one can notice the maturation of granulation tissue, which is manifested by a decrease in the number of microvascular loops, as well as the number of cellular elements. This is accompanied by the multiplication of fibrous structures of varying degrees of maturity. Morphological changes, compared, in the zone of implantation of cobalt-based alloys give confidence to state that after implantation of the Cerium alloy, healing and scarring of the wound surface occur faster than in previous cases.

In the morphological study of histological preparations of the capsule wall around the sample of the metal alloy "Dent-NCB" 2 weeks after the beginning of the experiment, it was revealed that the inner layer of the capsule is rather thick, consists of poorly differentiated thin fibers of connective tissue. Attention is drawn to the fact that the contours of the capsule are rather sinuous, and in some areas the inner layer is stratified. In addition, it should be noted that communication with the outer layer is broken in places, apparently due to the accumulation of exudate, produced by hyperemic microvessels.

The papillary protrusions of the walls of the capsule are deformed and fit tightly to its inner surface. On longitudinal sections of these formations in their thickness, there are accumulations of thin-walled hyperemic microvessels. After a month, the histological picture of the tissues surrounding the experimental sample of the alloy "Dent-NCB" changes slightly. In some areas of the inner layer of the capsule, numerous hyperemic vessels are still preserved, which can be a source of plasmorrhage and hemorrhage in the capsule cavity. In the outer layer, there is a noticeable maturation of granulation tissue, which is manifested by a significant decrease in the number of blood vessels, as well as cellular elements. Along with this, the proliferation of collagen structures of a high degree of maturation occurs.

When analyzing the structures of the capsule wall, formed in response to the implantation of the "Cellite-N" alloy, a peculiar histological picture appears, which is significantly different from the previous three. So, during the study of the capsule two weeks after the start of the experiment, a sharp fiber growth of the inner layer formed by connective tissue fibers of varying degrees of maturity is determined. In places of compact arrangement of fibrous structures, foci of their destruction are revealed with the subsequent formation of cavities. It should be noted that the papillary appearances of the capsule in this case are formed almost exclusively by the inner fibrous layer and do not have blood vessels. The latter are found only along the border of both layers, that is, external and internal. By the end of the experimental period, that is, one month after its beginning, further structural transformations of the capsule walls into the test sample are noticeable. First, there is a sharp defibering of the inner layer, in places its stratification from the outer; in addition, there is significant edema in the outer layer in the form of the formation of separate channels and cavities of different sizes, which leads to a sharp deformation of the capsule wall itself.

\section{DISCUSSION}

Summarizing the stated factual material, it can be stated that, despite the unification of the experiment, in all cases of implantation of various alloys, the tissue response was not the same $[1,6,8]$. In all research series of the experiment, the results of implantation of prototypes of metal alloys under the skin of animals were observed after 2 weeks of the formation of a thin-walled capsule $[2,11]$.

A careful histological analysis of the capsules formed around the metal alloy samples during two periods of the experiment showed that the healing time of the subcutaneous tissue was not the same. The most complete healing, that is, the formation of mature fibrous connective tissue, occurred during the implantation of the cobaltbased alloy «Remanium-2000» $[8,12]$. The thickness of both the inner and outer layers along the entire perimeter of the sample bed is not the same. It is characteristic that the inner layer of the capsule in different areas is represented by fibrous structures of various degrees of maturity, it is well manifested in different color densities of histological preparations. As in the previous case, the wall of the capsule forms protrusions into its cavity. and the capsule formed at the end of the experiment around the implanted sample from the «Shot-alloy» alloy, and during the implantation of the "Cerium» alloy, healing the wound surface and the formation of a connective tissue capsule occurs fully than in previous cases $[2,3,10]$.

After implantation of nickel-based alloys «Dent-NCB» and «Cellite-N». The histological picture appears, which is significantly different from the previous three. During the study of the capsule two weeks after the start of the experiment, a sharp fiber growth of the inner layer formed by connective tissue fibers of varying degrees of maturity is determined $[11,13,14]$. In places of compact arrangement of fibrous structures, foci of their destruction are revealed with the subsequent formation of cavities. It should be noted that the papillary appearances of the capsule in this case are formed almost exclusively by the inner fibrous layer and do not have blood vessels $[9,14]$.

The morphological picture of healing even after 1 month corresponds to the initial stages of this process, which indicates the influence of some inhibitory factors. Morphological changes during the formation of capsules around the implanted research alloys, as shown on histological preparations, indicate that maturation of connective tissue structures on the alloys of the cobaltchromium base occurs fully and faster.

\section{CONCLUSIONS}

The analysis of the performed experiment testifies in favor of the point of view that the speed and quality of healing of damaged subcutaneous tissue upon the introduction of 
implanted research alloys depend largely on the individual chemical components that make up the alloys, or on their combination.

\section{REFERENCES}

1. Hasiuk P., Vorobets A., Hasiuk N. et al. Sex differences of odontometrical indexes crowns of molars. Interventional Medicine and Applied Science. 2017;9(3):160-163.

2. Hasiuk P., RadchukV., Hasiuk N. et al. Fixed prosthetic constructions with using of high volume digital scanning techniques. World of medicine and biology. 2017;4(62):15-17.

3. Radchuk V., Hasiuk N., Yeroshenko G. Analiz structury ortopedychnoyi patolohiyi ta chastity povtornykh zvernen' pislya protezuvannya metalokeramichnymy konstruktsiyamy [Analysis of the orthopedic pathology structure and the frequency of repeated visits after dental prosthetics with metal-ceramic structures]. World of medicine and biology. 2019;4(70):138-142.( In Ukrainian).

4. Dahl B.E., Dahl J.E., Ronold H.J. Digital evaluation of marginal and internal fit of single-crown fixed dental prostheses. Eur J Oral Sci. 2018;126(6):512-517.

5. Sailer l., Balmer M., Hüsler J. et al. 10-year randomized trial (RCT) of zirconia-ceramic and metal-ceramic fixed dental prostheses. J Dent. 2018;76:32-39.

6. Lemos C.A.A., Verri F.R., Gomes J.M.L. et al. Ceramic versus metal-ceramic implant-supported prostheses: A systematic review and meta-analysis. J Prosthet Dent. 2019;121(6):879-886.

7. Pang Z., Chughtai A., Sailer I., Zhang Y. A fractographic study of clinically retrieved zirconia-ceramic and metal-ceramic fixed dental prostheses. Dent Mater. 2015;31(10):1198-1206.

8. Tanoue N. Longevity of resin-bonded fixed partial dental prostheses made with metal alloys. Clin Oral Investig. 2016;20(6):1329-1336.

9. Di Fiore A., Savio G., Stellini E. et al. Influence of ceramic firing on marginal gap accuracy and metal-ceramic bond strength of 3D-printed Co-Cr frameworks. J Prosthet Dent. 2020;124(1):75-80.

10. Önöral Ö., Ulusoy M., Seker E., Etikan I. Influence of repeated firings on marginal, axial, axio-occlusal, and occlusal fit of metal-ceramic restorations fabricated with different techniques. J Prosthet Dent. 2018;120(3):415-420.

11. Ramus M. Stan tkanyn biolohichnych obyektiv pid vplyvom splaviv metaliv (eksperymental'ne doslidzehennya). [The tissue condition of biological objects under the influence of metal alloys (experimantal study)]. Dental Science and Practice. 2015;1-2(6-7):6-13. (In Ukrainian).

12. Yanishen I., Tkachenko I., Skrypnikov P. et al. Wear resistance of dental materials which are used for anterior teeth restorations. Wiad. Lek. 2020;73(8):1677-1680.
13. Fastovets 0., Masheiko I., Lukash A. Evaluation of bone resorptive potential in the treatment of generalized periodontitis. Wiad. Lek. 2020;73(11):2396-2402.

14. Hasiuk P., Hasiuk N., Kindiy D. et al. Characteristics of cellular composition of periodontal pockets. Interventional Medicine \& Applied Science. 2016;8(4):172-177.

The work is a fragment of the research work of the orthopedic dentistry department I. Horbachevsky Ternopil National Medical University "Multidisciplinary approach to the study of the pathogenesis and treatment of main dental diseases based on the study of mechanisms of damage to the tissues of the oral cavity against the background of concomitant somatic pathology» (State Registration No. 0119U002431).

\section{ORCID and contributionship:}

Petro A. Hasiuk: 0000-0002-2915-0526 ${ }^{D}$

Mykhailo Ramus: 0000-0003-4040-6905 ${ }^{D}$

Anna Vorobets: 0000-0002-4119-7896 ${ }^{B}$

Iryna Tkachenko: 0000-0001-8243-8644 ${ }^{\mathrm{F}}$

Tetiana Dzetsiukh: 0000-0001-7163-1844 ${ }^{\mathrm{C}}$

Dmytro Kalashnikov: 0000-0002-4825-059X ${ }^{E}$

Svitlana Rosolovska: 0000-0003-4768-3905 A,F

\section{Conflict of interest:}

The Authors declare no conflict of interest.

\section{CORRESPONDING AUTHOR}

\section{Petro A. Hasiuk}

I. Horbachevsky Ternopil National Medical University

1 Maidan Voli, 46001 Ternopil, Ukraine

tel: +380961445444

e-mail: gasiukpa@tdmu.edu.ua

Received: 22.09 .2020

Accepted: 02.06 .2021

A - Work concept and design, B - Data collection and analysis, C - Responsibility for statistical analysis,

D-Writing the article, E-Critical review, F- Final approval of the article 